\title{
HUBUNGAN PERAN AKTIF IBU DALAM KEGIATAN POSYANDU DENGAN STATUS GIZI BALITA DI WILAYAH KERJAPUSKESMAS KUTA BARO ACEH BESAR
}

\author{
The Relationship Of The Active Role Of Mother In Posyandu Activities
}

With The Nutritional Status Of Children In The Cooperative

\author{
Area Of Kuta Baro Aceh Besar \\ Zulfahmi*1 $^{*}$, Nurul Fahmi ${ }^{2}$ \\ ${ }^{1,2}$ Fakultas Ilmu Kesehatan, Universitas Ubudiyah Indonesia, Banda Aceh \\ Email: zulfahmi@uui.ac.id"1 ${ }^{* 1}$ nurulfah45@yahoo.com²
}

\begin{abstract}
ABSTRAK
Posyandu merupakan salah satu pelayanan kesehatan di desa untuk memudahkan masyarakat mengetahui atau memeriksakan kesehatan terutama ibu hamil dan anak balita. Peran aktif ibu pada setiap kegiatan posyandu tentu akan berpengaruh pada keadaan status gizi anak balitanya. Tujuan Penelitian : mengetahui Hubungan peran aktif ibu dalam kegiatan posyandu dengan status gizi balita di wilayah kerja Puskesmas Kuta Baro Aceh Besar. Metode Penelitian : Bersifat Analitik dengan pendekatan cross sectional. Tehnik pengambilan sampel menggunakan tehnik proporsional random sampling dengan populasi 167 orang dan didapatkan 93 responden. Penelitian dilakukan tanggal 7 s/d $12-$ 7-2014. Pengumpulan melalui penyebaran kuesioner, selanjutnya dilakukan uji statistik dengan menggunakan Chi-Square test

memakai program SPSS versi 13 for windows dengan tingkat kepercayaan $95 \%$ dan batas kemaknaan $(\alpha=0,05)$ Ho ditolak jika $p$ value $>0,05$ dan Ha diterima jika $p$ value $<0,05$. Hasil Penelitian: terdapat pengetahuan yang baik sebanyak 48 responden $(72,7 \%)$ memiliki status gizi baik dengan p-value $=0,001$. Dan informasi baik sebanyak 34 responden $(87,2 \%)$ memiliki status gizi baik dengan $p$-value $=0,000$. Serta mayoritas ibu berperan aktif dengan status gizi baik sebanyak 41 responden $(74,5 \%)$ dengan p-value $=0,003$. Kesimpulan : Hasil analisa statistik menyatakan bahwa Ada hubungan pengetahuan, informasi dan peran aktif ibu dengan status gizi balita dalam kegiatan posyandu di desa dalam wilayah kerja Puskesmas Kuta Baro Aceh Besar. Diharapkan kepada ibu agar dapat mengetahui dan paham tentang status gizi balita Diharapkan juga kepada tenaga kesehatan agar dapat memberikan konseling dan informasi kepada ibu balita agar memerhatikan status gizi balitanya dengan datang ke posyandu setiap bulannya.
\end{abstract}

\section{Kata Kunci : status gizi balita, pengetahuan, informasi dan peran aktif ibu}

\begin{abstract}
Posyandu is one of the health services in the village to facilitate the public to know or check their health, especially pregnant women and children under five. The active role of the mother in every posyandu activity will certainly affect the nutritional status of her toddler. Objective: To find out the relationship between the mother's active role in posyandu activities and the nutritional status of children under five in the work area of the Kuta Baro Health Center in Aceh Besar. Research Methods: Analytical with cross sectional approach. The sampling technique uses proportional random sampling technique with a population of 167 people and obtained 93 respondents. The study was conducted from 7 to 12-7-2014. Collection by distributing questionnaires, then performed statistical tests using the ChiSquare test
\end{abstract}


Journal of Healthcare Technology and Medicine Vol. 5 No. 1 April 2019

Universitas Ubudiyah Indonesia

e-ISSN : 2615-109X

using SPSS version 13 for windows with a 95\% confidence level and significance limit ( $\alpha$ $=0.05)$ Ho is rejected if $p$ value $>0.05$ and Ha is accepted if $p$ value <0.05. Results: There was good knowledge as many as 48 respondents (72.7\%) had good nutritional status with p-value $=0.001$. And good information as many as 34 respondents $(87.2 \%)$ have good nutritional status with $p$-value $=0,000$. And the majority of mothers play an active role with good nutritional status as many as 41 respondents $(74.5 \%)$ with p-value $=0.003$. Conclusion: The results of the statistical analysis state that there is a relationship between knowledge, information and the active role of the mother with the nutritional status of children under five in the Posyandu activities in the village within the working area of the Kuta Baro Aceh Besar Puskesmas. It is expected that mothers be able to know and understand the nutritional status of children under five. It is also expected that health workers can provide counseling and information to mothers of children under five to pay attention to their toddler's nutritional status by coming to the posyandu every month.

Keywords: nutritional status of toddlers, knowledge, information and active role of mothers

\section{PENDAHULUAN}

Millenium Development Goals (MDG's) adalah upaya untuk memenuhi hak-hak dasar kebutuhan manusia melalui komitmen bersama antara 189 negara anggota PBB. Menurut data yang di tunjukkan oleh mdg's, angka malnutrisi (kekurangan gizi) bagi anak usia di bawah lima tahun pada tahun

1990 sebesar 35,5\% dan menurun pada saat ini sebesar 28,7\%. Target yang ingin di capai pada tahun 2015 sebesar 18\%. Hal ini mengharuskan pemerintah dan petugas kesehatan untuk terus berusaha lebih keras agar target yang telah di tentukan tercapai. (Peter, 2008)

Kasus gizi buruk yang menimpa anak-anak dibawah umur 5 tahun (balita) juga terjadi di berbagai daerah di Jawa Barat. Status gizi balita di kabupaten Bandung pada tahun 2006 menunjukkan balita dengan status gizi kurang sebesar 1,31\% dan balita dengan status gizi buruk sebesar $0,92 \%$. Jumlah penderita, rata-rata naik di banding tahun sebelumnya (Profil Kesehatan Kab. Bandung Tahun 2006).

Usaha Perbaikan Gizi Keluarga (UPGK) yang dilakukan selama ini di titik beratkan pada penggunaan pesan-pesan gizi sederhana melalui kegiatan yang dapat di lakukan masyarakat sendiri. Kegiatan tersebut di pusatkan di posyandu yang merupakan UKBM (Upaya Kesehatan Bersumber Daya Masyarakat) yang paling memasyarakat dewasa ini. Posyandu yang meliputi lima program prioritas yaitu : KB, KIA, gizi, imunisasi, dan penanggulangan diare dengan sasaran bayi, anak balita, pasangan usia subur dan ibu hamil. Penyuluhan kesehatan, pemberian makanan tambahan, tablet vitamin A dosis tinggi, pemberian oralit, dan terbukti mempunyai daya ungkit besar terhadap angka kematian bayi (Supariasa, 2005). 
Journal of Healthcare Technology and Medicine Vol. 5 No. 1 April 2019

Universitas Ubudiyah Indonesia

e-ISSN : 2615-109X

Posyandu merupakan salah satu pelayanan kesehatan di desa untuk memudahkan masyarakat untuk mengetahui atau memeriksakan kesehatan terutama untuk ibu hamil dan anak balita. Peran aktif keluarga pada setiap kegiatan posyandu tentu akan berpengaruh pada keadaan status gizi anak balitanya, karena salah satu tujuan posyandu adalah memantau peningkatan status gizi masyarakat terutama anak balita dan ibu hamil (Adisasmito, 2007).

Sedangkan untuk posyandu yang dilaksanakan 1 bulan sekali oleh posyandu diwilayah kerja Puskesmas Kuta Baro Aceh Besar dari seluruh jumlah balita yang ada hanya sebagian kecil yang datang ke posyandu. Berarti masih banyak ibu yang tidak membawa balitanya datang untuk mendapatkan pelayanan posyandu. Berdasarkan hasil wawancara awal dengan beberapa ibu yang datang ke posyandu, bahwa ibu tersebut dan ibu-ibu yang tidak datang itu beralasan jika tidak datang karena urusan merasa apa yang di sampaikan tidak penting dan membuang waktu, ini disebabkan karena ibu tersebut kurang mendapat informasi apa saja yang di sampaikan di posyandu dan pengetahuan yang cukup tentang kegiatan posyandu. Kegiatan posyandu yang dilaksanakan sangatlah penting, untuk membantu ibu-ibu dalam menyiapkan makanan dan kesehatan yang benar bagi balitanya. Dengan menyiapkan makanan dan kesehatan sejak dini, maka akan di dapatkan balita dan anak yang tumbuh dengan sehat dan memiliki gizi seimbang.

Oleh karena itu, peneliti tertarik untuk mengadakan penelitian untuk mengetahui adakah hubungan peran aktif ibu dalam kegiatan posyandu dengan status gizi balita di wilayah kerja Puskesmas Kuta Baro Aceh Besar.

\section{METODE PENELITIAN}

Penelitian ini merupakan penelitian yang bersifat Analitik, dengan menggunakan pendekatan Cross Sectional yaitu suatu rancangan penelitian dengan melakukan pengukuran atau pengamatan pada saat bersamaan (sekali waktu). Dalam hal ini peneliti ingin mengetahui Hubungan peran aktif keluarga dalam kegiatan posyandu dengan status gizi balita di wilayah kerja Puskesmas Kuta Baro Aceh Besar.

Populasi dalam penelitian ini adalah seluruh ibu yang mempunyai balita dan berkunjung ke posyandu di 48 desa dalam wilayah kerja Puskesmas Kuta Baro Aceh Besar yang berjumlah 1248 Orang.

Alat yang digunakan untuk untuk pengumpulan data dalam penelitian ini adalah kuesioner yang berisi 27 pertanyaan dalam bentuk Dichotomous Choise, yang terdiri dari 
Journal of Healthcare Technology and Medicine Vol. 5 No. 1 April 2019

Universitas Ubudiyah Indonesia

e-ISSN : 2615-109X

1) Pengetahuan, mengajukan 10 pertanyaan dengan alternatif jawaban "Ya" dan "Tidak"

2) Informasi, mengajukan 10 pertanyaan dengan alternatif jawaban "Ya" dan

"Tidak"

3) Peran Aktif Keluarga, mengajukan 7 pertanyaan dengan alternatif jawaban

"Ya" dan "Tidak"

4) Status gizi pada balita dengan kegiatan posyandu, dengan melihat buku KIA untuk mengukur berat badan di lakukan penimbangan.

Untuk tabel indeks berat badan menurut umur dapat dilihat dilampiran. Dan tabel hasil penilaian berdasarkan rumus diatas, yaitu:

\begin{tabular}{|c|c|}
\hline Status Gizi & Nilai Z-Score \\
\hline Gizi Buruk & $<-3,0$ \\
\hline Gizi Kurang & $\geq-3,0 \mathrm{~s} / \mathrm{d}<-2,0$ \\
\hline Gizi Baik & $\geq-2,0 \mathrm{~s} / \mathrm{d} \leq 2,0$ \\
\hline Gizi Lebih & $>2,0$ \\
\hline
\end{tabular}

Untuk pemberian skor dari tiap variabel, dengan kriteria :

(1) Bila pertanyaaan positif, Jawaban "Ya" di beri nilai 1 dan jawaban "Tidak" diberi nilai 0

(2) Bila pertanyaan negatif, Jawaban "Ya" diberi nilai 0 dan jawaban "Tidak" diberi nilai 1

\section{HASIL DAN PEMBAHASAN}

\section{Hubungan Pengetahuan Dengan Status gizi}

Tabel 1

Hubungan pengetahuan Dengan Status gizi Pada Responden dalam kegiatan posyandu di wilayah kerja

Puskesmas Kuta Baro Aceh Besar.

\begin{tabular}{|c|c|c|c|c|c|c|c|c|}
\hline \multirow{2}{*}{$\begin{array}{l}\text { N } \\
\text { N }\end{array}$} & Pengetahuan & \multicolumn{3}{|c|}{ Status Gizi } & \multicolumn{2}{|c|}{ Total } & \multirow{2}{*}{ P } \\
\cline { 3 - 8 } & & \multicolumn{2}{|c|}{ Baik } & \multicolumn{2}{|c|}{ Buruk } & \multicolumn{2}{|c|}{} \\
\cline { 2 - 8 } & f & $\%$ & F & $\%$ & f & $\%$ & \\
\hline 1 & Baik & 48 & 72,7 & 18 & 27.3 & 66 & 100 & \multirow{2}{*}{0,001} \\
\hline 2 & Kurang Baik & 9 & 33,3 & 18 & 66.7 & 27 & 100 & \\
\hline & Total & 57 & & 36 & & 93 & & \\
\hline
\end{tabular}


Journal of Healthcare Technology and Medicine Vol. 5 No. 1 April 2019

Universitas Ubudiyah Indonesia

e-ISSN : 2615-109X

Dari hasil analisa statistik menggunakan uji chi-square menunjukkan hubungan tersebut bermakna dengan nilai $\alpha=0,05$ dan $\mathrm{p}$ value $=0,001$. Hal tersebut berarti hipotesis penelitian menyatakan bahwa ada hubungan antara pengetahuan dengan status gizi bailta terbukti atau dapat diterima.

Penelitian ini sesuai dengan teori yang dikemukakan oleh (Sediaoetama, 2006), Pengetahuan gizi yang baik akan menyebabkan seseorang mampu menyusun menu yang baik untuk dikonsumsi. Semakin banyak pengetahuan gizi seseorang, maka ia akan semakin memperhitungkan jenis dan jumlah makanan yang diperolehnya untuk dikonsumsi

Pengetahuan dapat membentuk suatu sikap dan menimbulkan suatu perilaku dalam kehidupan sehari-hari (Notoatmodjo,2009). Kurangnya pengetahuan sering di jumpai sebagai faktor yang penting dalam masalah pemanfaatan meja penyuluhan, karena kurangnya penyuluhan kesehatan sehingga pengetahuan anggota masyarakat khususnya ibu-ibu yang memiliki balita juga memiliki pengetahuan yang minim (Sediaotama, 2006).

\section{Hubungan Informasi Dengan Status gizi}

\section{Tabel 2}

Hubungan Informasi Dengan Status gizi Pada Responden dalam kegiatan posyandu di wilayah kerja Puskesmas Kuta Baro Aceh Besar.

\begin{tabular}{|c|c|c|c|c|c|c|c|c|}
\hline \multirow{3}{*}{$\begin{array}{l}\mathrm{N} \\
\mathrm{O}\end{array}$} & \multirow[t]{3}{*}{ Informasi } & \multicolumn{4}{|c|}{ Status Gizi } & \multirow{2}{*}{\multicolumn{2}{|c|}{ Total }} & \multirow[b]{2}{*}{$\mathrm{p}$} \\
\hline & & \multicolumn{2}{|c|}{ Baik } & \multicolumn{2}{|c|}{ Buruk } & & & \\
\hline & & $\mathrm{f}$ & $\%$ & $\mathrm{~F}$ & $\%$ & $\mathrm{f}$ & $\%$ & \multirow{4}{*}{0,000} \\
\hline 1 & Baik & 34 & 87,2 & 5 & 12.8 & 39 & 100 & \\
\hline 2 & Cukup & 18 & 62,1 & 11 & 37.9 & 29 & 100 & \\
\hline \multirow[t]{2}{*}{3} & Kurang & 5 & 20,0 & 20 & 80.0 & 25 & 100 & \\
\hline & Total & 52 & & 36 & & 93 & & \\
\hline
\end{tabular}

Dari hasil analisa statistik menggunakan uji chi-square menunjukkan hubungan tersebut bermakna dengan nilai $\alpha=0,05$ dan $\mathrm{p}$ value $=0,000$. Hal tersebut berarti hipotesis penelitian menyatakan bahwa ada hubungan antara status gizi dengan informasi terbukti atau dapat diterima.

Penelitian ini sesuai dengan teori yang dikemukakan oleh (Notoatmodjo, 2009), informasi identik dengan wujud material yang dapat dikirimkan dan diterima melalui berbagai saluran, baik melalui media tulisan (poster gizi) dan lisan (berbicara langsung 
Journal of Healthcare Technology and Medicine Vol. 5 No. 1 April 2019

Universitas Ubudiyah Indonesia

e-ISSN : 2615-109X

dengan penyuluh atau kader posyandu). Karena itu menurut pandangan ini kualitas informasi dapat dihitung dalam arti makin banyak usaha seseorang mengumpulkan data dan fakta, makin banyak informasi yang dimilikinya. Informasi tentang tumbuh kembang balita yang di dapat di posyandu dapat membantu keluarga dalam pemenuhan gizi bagi balita, gizi di sini yaitu cara menyiapkan nutrisi yang baik dan seimbang.

Menurut asumsi peneliti bahwa pemberian gizi yang baik dan seimbang sangat di pengaruhi sejauh mana si ibu tersebut mendapatkan informasi tidak hanya dari keluarga atau teman yang memberikan informasi secara verbal, tetapi juga dapat di tanyakan kebenarannya pada petugas di posyandu. Informasi yang berguna dapat membantu ibu untuk dapat lebih memperhatikan tumbuh kembang balitanya.

\section{Hubungan Peran Aktif Ibu Dengan Status gizi}

\section{Tabel 3}

Hubungan Peran Aktif Ibu Dengan Status gizi Pada Responden dalam kegiatan posyandu di wilayah kerja Puskesmas Kuta Baro Aceh Besar.

\begin{tabular}{|c|c|c|c|c|c|c|c|c|}
\hline \multirow{3}{*}{$\begin{array}{l}\mathrm{N} \\
\mathrm{o}\end{array}$} & \multirow{3}{*}{$\begin{array}{l}\text { Peran } \\
\text { Ibu }\end{array}$} & \multicolumn{4}{|c|}{ Status Gizi } & \multirow{2}{*}{\multicolumn{2}{|c|}{ Total }} & \multirow[b]{2}{*}{$\mathrm{p}$} \\
\hline & & \multicolumn{2}{|c|}{ Baik } & \multicolumn{2}{|c|}{ Buruk } & & & \\
\hline & & $\mathrm{F}$ & $\%$ & $\mathrm{f}$ & $\%$ & $f$ & $\%$ & \\
\hline 1 & Aktif & 41 & 74,5 & 14 & 25.5 & 55 & 100 & \\
\hline 2 & Tidak Aktif & 16 & 42,1 & 22 & 57.9 & 38 & 100 & 0,003 \\
\hline & Total & 57 & & 36 & & 93 & & \\
\hline
\end{tabular}

Dari hasil analisa statistik menggunakan uji chi-square menunjukkan hubungan tersebut bermakna dengan nilai $\alpha=0,05$ dan $\mathrm{p}$ value $=0,003$. Hal tersebut berarti hipotesis peneltian yang menyatakan bahwa ada hubungan antara peran aktif ibu dengan status gizi balita terbukti atau dapat diterima.

Penelitian ini sesuai dengan teori yang dikemukakan oleh Notoatmodjo (2007) dimana struktur keluarga (suami) dapat mempunyai pengaruh terhadap pemanfaatan pelayanan kesehatan suatu keluarga. Dukungan suami sangat berperan dalam memelihara dan mempertahankan status gizi balita yang optimal.

Setiadi (2008) juga mengatakan hal yang serupa yaitu Peran serta keluarga di maksud adalah keluarga yang ikut turut andil dalam berbagai usaha untuk memajukan anggota keluarga yang lain atau memberikan semangat dan waktu untuk membantu usaha 
Journal of Healthcare Technology and Medicine Vol. 5 No. 1 April 2019

Universitas Ubudiyah Indonesia

e-ISSN : 2615-109X

yang akan dilakukan. Peran serta keluarga dalam kegiatan posyandu yaitu turut sertanya keluarga dalam kegiatan yang dilakukan oleh posyandu, misalnya membawa balitanya untuk mengukur berat badan, pemberian nutrisi yang tepat.

\section{KESIMPULAN}

Setelah dilakukan penelitian dan uji statistik tentang hubungan peran aktif ibu dalam kegiatan posyandu dengan status gizi balita di dalam wilayah kerja Puskesmas Kuta Baro Aceh Besar, dapat disimpulkan sebagai berikut :

1. Ada hubungan antara pengetahuan dalam kegiatan posyandu dengan status gizi balita di dalam wilayah kerja Puskesmas Kuta Baro Aceh Besar dengan p-value = 0,001 .

2. Ada hubungan antara informasi dalam kegiatan posyandu dengan status gizi balita di dalam wilayah kerja Puskesmas Kuta Baro Aceh Besar dengan p-value = 0,000

3. Ada hubungan antara peran aktif ibu dalam kegiatan posyandu dengan status gizi balita di dalam wilayah kerja Puskesmas Kuta Baro Aceh Besar dengan p-value $=0,003$.

\section{DAFTAR PUSTAKA}

Adisasmito, W. (2007) Sistem Kesehatan. Jakarta: PT. Raja Grafindo Persada Almatsier, S. (2007) Prinsip Dasar Ilmu Gizi. Jakarta : Gramedia Pustaka Umum Almatsier, S. (2007) Prinsip Dasar Ilmu Gizi. Jakarta : Gramedia Pustaka Umum. Di Puskesmas Perembeu Kecamatan Kawai XVI Kabupaten Aceh Barat. Hartati. (2013) Faktor-Faktor Yang Berhubungan Dengan Status Gizi Pada Balita Hidayat A. (2007) Metodologi Penelitian Kebidanan Dan Teknik Analisa Data. Jakarta: Salemba Medika.

Menkes RI. (2010) Antropometri Penilaian Status Gizi Anak. Jakarta : KEMENKES RI Notoatmodjo. (2009) Pendidikan Dan Perilaku Kesehatan. Jakarta: Rineka Cipta.

Radiansyah. (2007) Gizi Balita dalam http://www.radiansyah.com/gizi/balita Setiadi. (2008). Konsep dan Penulisan Riset Keperawatan Edisi 1. Yogyakarta: Graha Ilmu

Supariasa. (2005) Penilaian Status Gizi. Jakarta: Buku Kedokteran EGC. 
Journal of Healthcare Technology and Medicine Vol. 5 No. 1 April 2019

Universitas Ubudiyah Indonesia

e-ISSN : 2615-109X 
Journal of Healthcare Technology and Medicine Vol. 5 No. 1 April 2019

Universitas Ubudiyah Indonesia

e-ISSN : 2615-109X 
Journal of Healthcare Technology and Medicine Vol. 5 No. 1 April 2019

Universitas Ubudiyah Indonesia

e-ISSN : 2615-109X 
